\title{
THE USE OF CITIZEN JOURNALISM FOR HYPERLOCAL NEWS PRODUCTION
}

\author{
Evelien D'heer and Steve Paulussen ${ }^{1}$
}

This paper describes the case of the hyperlocal media project of the Belgian newspaper Het Belang van Limburg. In 2011 the newspaper launched a platform, called Het Belang van mijn gemeente, which makes use of citizen journalism for the coverage of local community news. The newspaper actively encourages community members (i.e. citizens, local councils and organizations) to contribute stories to the local news pages on the newspaper's website. For each municipality in the province of Limburg, a local news page is created where people who have registered themselves as a news hunter can publish their own news stories, pictures and event announcements. All citizen contributions are published next to the professionally made news articles from the newspaper's local journalists. Since the professional editorial content and the user-generated news content are not separated but co-exist within the same online news environment, it is interesting to investigate similarities and complementarities between both types of content. The central research question of this paper therefore is to what extent and in which ways contributions by local citizen journalists differ from the professional editorial news content in terms of topic selection and the use of sources.

1 Evelien D'heer is Junior Researcher at the Department of Communication Studies at the University Ghent. Steve Paulussen is an Assistant Professor in Media and Journalism Studies at the University of Antwerp.

Recherches en communication, $\mathrm{n}^{\circ} 39$ (2013). 


\section{The rise of hyperlocal journalism}

In a blog post in 2004, new media expert and blogger Jeff Jarvis (2004) used the term hyperlocal to point out the potential of citizen journalism for local news coverage. In the following years, the term was picked up in scholarly and professional literature to refer to news about local events and community activities within a narrow geographic area, such as a small town or a neighborhood. Also in 2004, Dan Gillmor published his influential book "We the Media", in which he argued that journalism would (and should) be evolving from a lecture to a conversation, since users were increasingly getting involved in the production and distribution of news. The rise of citizen journalism and its impact on professional journalism has received much scholarly attention. This resulted in a range of studies on the use of user-generated content in professional news production (see Domingo et al., 2008; Hermida \& Thurman, 2008; Jönsson \& Örnebring, 2011; Singer et al., 2011). While most of these studies on participatory journalism focus on national media, such as public broadcasters and national online newspapers, less attention has been paid to the potential of grassroots journalism for local or hyperlocal media production (but see Metzgar, Kurpius \& Rowley, 2011; Bruns, 2011).

Metzgar et al. (2011) use six criteria to define hyperlocal media operations. In their definition, "hyperlocal media operations are geographically-based, community-oriented, original-news-reporting organizations indigenous to the web and intended to fill perceived gaps in coverage of an issue or region and to promote civic engagement" (Metzgar et al., 2011, p. 774). It is important to note that in their conceptualization, hyperlocal journalism is restricted to online-only, web native, grassroots initiatives. These community operations are mostly originated from the bottom up and often (though not necessarily) maintained by nonprofit organizations. In recent years, however, we see that in different countries commercial regional newspapers have jumped on the hyperlocal bandwagon by creating (top-down) their own hyperlocal platforms. According to Flew (2009), this shift towards the hyperlocal is part of the newspapers' strategies to make the transition to the digital environment and consolidate their position in a highly competitive market. As Flew (2009, pp. 98-99) suggests, hyperlocal media projects allow regional newspapers to expand their reputation as trusted news brands from the print to the digital environment; to reduce costs by outsourcing parts of the production process to voluntary citizen 
journalists (cf. Vujnovic et al., 2010); and to attract potential new users by targeting narrow geographic areas and niche audience segments.

For their hyperlocal media projects, regional newspapers can build on their experience in covering community news. Contrary to their colleagues working for national news media, local journalists have always been involved in providing news about the town council, community service information and human interest stories, added with reports on regional economy and crimes (Ross, 2006). Franklin (1998) shows that many of the news stories in free local newspapers have a human-interest focus, while Bew (2006, pp. 203-204) describes how, in order to "cover every spit and cough", local newspapers maintain large networks of "village pump correspondents who are paid retainers as freelancers to supply copy on everything from the local fete to the darts match". According to one of the local news editors she interviewed, "(p)eople today want 'really really' local news" (Bew, 2006, p. 204). Since hyperlocal news projects allow for publishing the most local news, they can be considered a logical online extension of community journalism (Reader \& Hatcher, 2012). Lauterer (2006) gives the following description of community journalism:

Small-j journalism, some call it. It's the kind of journalism practiced by newspapers where the readers can walk right into the newsroom and tell the editor what's on their minds. It's the kind of newspaper that covers the town council, prints the school lunch menus, leads the sports page with the high school football game, tells you who visited Aunt Susie last week and runs photos of proud gardeners holding oddly shaped vegetables. The paper is loaded with weddings, anniversaries, engagements, police blotter reports, sports statistics, births and obituaries (...) (Lauterer, 2006, p. 3).

As we will see below, the case discussed in this paper fits this definition of community journalism - or small-j journalism - quite well, except for the fact that it is no longer performed by professionals working for a print newspaper, but by amateurs contributing to a website. 


\section{Hyperlocal journalism at Het Belang van Limburg}

The Belgian newspaper Het Belang van Limburg, a Flemish (Dutchlanguage) daily owned by the media company Concentra, is the leading news brand in the province of Limburg, where it reaches over $80 \%$ of the newspaper readers. Online, the newspaper was the first in Belgium to explore the potential of citizen journalism and user-generated content for hyperlocal news production. In 2006, the company launched a project, called HasseltLokaal, that evolved into a local community website coordinated by a community manager, but maintained by a team of citizen reporters, who voluntarily covered local news stories from Hasselt, a city of about 70,000 people (Paulussen \& Ugille, 2008). The success of this hyperlocal project inspired the newspaper to look for ways to expand the project to other municipalities in the province.

In 2011, Het Belang van Limburg launched the hyperlocal media project Het Belang van mijn gemeente or The Interest of my town. For each municipality in the province of Limburg, a page was created on the newspaper's website, where citizens, local councils and organizations, who have registered themselves on the project's platform, can publish their own news stories, pictures and event announcements. The province of Limburg counts 44 municipalities. Each of them has a dedicated news page on the newspaper website: news from the city of Hasselt is located on the web page of Het Belang van Hasselt, news from the municipality Bilzen can be found on the page of Het Belang van Bilzen, and so on.

All citizen contributions are published on the website with no or little adjustments, where they appear next to the professionally made news articles from the newspaper's local editors. In order to motivate as much residents as possible to register themselves as citizen reporters - or news hunters, as they are called by the newspaper - on the online platform, the newspaper stresses that all kinds of contributions are welcome and will be published on the web pages without any significant intervention by the professional editors at the newspaper. For the promotion campaign of the project, the newspaper initially used the slogan 'Alles is nieuws' ('Everything is news'). Later, the project's baseline was changed into 'Klein nieuws bestaat niet' ('Small news does not exist'). Both slogans indicate that the newspaper is aware that a lot of user-generated content deals with personal experiences or local events, which only appear relevant to a narrow community - some might call it small-j journalism (cf. supra). 
An important characteristic of the platform of Het Belang van mijn gemeente is that both professional and citizen content appear on the same web page with no specific hierarchy or other form of distinction apart from a small icon of a megaphone next to the name of citizen reporters. The fact that the user-generated content is not separated from the professional articles makes it an interesting case to examine commonalities and differences between both types of community reporting.

\section{Aim of the study}

The aim of our empirical study was to investigate to what extent and in which ways user-generated news contributions to the hyperlocal web pages of Het Belang van mijn gemeente differ from the professional articles in terms of topic selection and the use of sources. In doing so, the study aims to contribute to our knowledge on the use and potential of citizen journalism for news making at the hyperlocal level ${ }^{1}$.

For the purpose of our study, we conducted a content analysis of the topics covered on the hyperlocal news pages and the sources used by the producers of the content. The content analysis was supplemented with in-depth interviews with ten citizen reporters in order to gain a better insight in their motivations, news judgment and sourcing practices. Hence, this study seeks to provide answers to two main research questions.

RQ1: What are the dominant story categories of the content covered by citizen and professional journalists on the hyperlocal media platform?

Drawing on the literature review, we expected that the hyperlocal news pages would be dominated by soft news stories on human-interest topics, community issues and local cultural and sports events. Local newspapers also tend to pay much attention to thefts, burglaries and acts of aggression in the neighborhood, traffic accidents and news from the local town councils (see Franklin, 2006; Franklin \& Murphy, 1998; Lauterer, 2006). The often-found personal angle of community news will probably be intensified by citizen contributions, since studies on user-generated content in the news have shown that people seem to

1 For a more extensive discussion of the empirical results from the content analysis, we refer to a forthcoming article in Journalism Practice (Paulussen \& D'heer, forthcoming). 
be most motivated to submit stories that closely relate to their own personal interests and experiences (Reich, 2008).

RQ2: What are the sources used by citizen and professional journalists in their coverage of hyperlocal news?

The few studies that have investigated sourcing practices in citizen journalism suggest that user-generated content is often selfreferential, by which we mean that the author is often also the main source of the story. A study of citizen journalists in Israel shows a high proportion of their stories being based on just one source (Reich, 2008). Due to their relatively limited access to official news sources, citizen reporters "tend to predicate their stories on firsthand witnessing, technical sources (mainly Internet), personal acquaintances, and on their own experience" (Reich, 2008, p. 739). One-source stories are also common in local journalism, although professional reporters are more likely to use official rather than non-official sources. Research on local newspapers in the UK has shown that local governments, the police and courts, and organizers of staged events are among the mostcited sources in local journalism (O'Neill \& O'Connor, 2008), and that economic pressures for cost efficiency force local journalists to rely on page-ready PR material and copy from press agencies (Garner, 2006; Hamer, 2006).

\section{Research design}

The study's research design combines a quantitative content analysis of a sample of news pages of Het Belang van mijn gemeente with ten in-depth interviews of citizen reporters. In this section, we briefly discuss the methodological aspects of the two parts of our empirical study.

\subsection{A quantitative content analysis}

We conducted a quantitative content analysis of ten municipal online news pages of the platform of Het Belang van mijn gemeente. As mentioned above, each of the 44 municipalities in the province of Limburg has its own web page on the platform, but for our study we only selected ten of them. The decision to analyze the news pages of ten randomly selected municipalities was based on practical considerations. Including all municipalities in the content analysis was not appropriate, because, at the time of our study, the content published 
on the hyperlocal news platform was not yet systematically archived by the news organization, so we had to manually capture and store all stories published on the pages on the days of our sampling. For the same reason, and given the newness of the project, opting for a constructed week was not appropriate either; hence, two consecutive weeks in November 2011 were used for the sampling. The 14-days sample provided us with a total of 319 news items. In order to make those results more generalizable over time and control for any changes that might have taken place since the first months after the launch of the project, an additional consecutive week was selected in June 2012. Overall, 474 news items were included in our content analysis. The coding was done by both authors of this article (for more details about the methodology of the content analysis, see also Paulussen \& D'heer, forthcoming).

\subsection{In-depth interviews}

In order to enrich and help validate the findings from the content analysis, ten in-depth interviews were conducted with citizen journalists. For each of the ten municipalities in the content analysis, the citizen reporters with the highest number of contributions were approached for an in-depth interview (two females, eight males, age ranging from 32 to 74). The semi-structured interviews took place in February-March 2012 and centered around the citizens' coverage of specific topics, the sources they used, and their motivations for being a citizen reporter. We adopted the methodology of reconstruction interview' as proposed by Reich (2009). This means that the discussion of the news practices is based on the reconstruction of the production of the particular stories. Per participant, the five most recent articles were chosen to ensure they could accurately recall their decisions made during the production of the story.

\section{Results}

Over the course of the three weeks in our sample, 474 articles were collected; $62 \%$ of them were citizen-generated, the remaining $38 \%$ were produced by professional journalists. In the following sections, we will describe the topics covered in the news items and the sources used by the citizen and professional journalists respectively. Data from 
the content analysis are supplemented with findings from the in-depth interviews.

\subsection{Hyperlocal news topics}

In general, the most frequent story categories on the hyperlocal news pages resemble those of local newspapers (Franklin, 2006): crime reporting tops the list with $26 \%$ of the items dealing with burglaries, violence, vandalism and court cases, followed by coverage of social club activities $(12 \%)$ and local cultural events $(12 \%)$. Also health and sportsrelated issues (12\%), stories about education and school life (10\%), and fires and traffic accidents (6\%) are popular topics in (hyper)local news. Compared to studies on local journalism, the pages of Het Belang van mijn gemeente contain relatively few human-interest stories (3\%), such as stories about exceptional personal achievements and sufferings, special anniversaries, etc. We must add, however, that many of the stories have a human-interested angle: for instance, reports on local festivities tend to mention names of local people 'worth mentioning', but these were not coded as human-interest stories. Notably, the number of items dealing with economy or politics is very low, namely less than two percent. This is partly due to the fact that local town councils registered on the platform focused mainly on service information, such as the announcement of construction works, opening hours of public service institutions, and upcoming cultural events. The professional journalists do not cover politics on the hyperlocal level at all.

A striking finding of our content analysis was that despite their appearance on the same pages, the user-generated stories differ almost completely from the professional news articles in terms of topics covered. The professional journalists almost exclusively focus on crimes, fires and accidents, whereas the soft news topics are mostly covered by citizens. The complementarity between the user-generated and professional stories suggests that citizen contributions are mainly used to "fill perceived gaps in coverage" of community issues, as has been suggested by Metzgar et al. (2011, p. 782; see also the abovementioned definition of hyperlocal media operations). It seems that the professional editorial team of Het Belang van Limburg has outsourced coverage of community life to the community itself, thus narrowing down its own role to moderating the platform and "filling perceived gaps" with reports on crimes and accidents. 
The in-depth interviews allow us to better understand citizen reporters' motivations and their position within their local community. Most interviewees registered themselves to the platform as members of a social club or organization, ranging from local schools over sports clubs to arts and culture organizations. Hence, most of their contributions deal with stories on social club activities and news or announcements from their organization. These interviewees did not have the ambition to report on other community issues. Sometimes, they only used the hyperlocal media platform to redistribute content from their organizations' website, as one interviewee told us:

Interviewer: Do you still write for other websites since you have registered for the hyperlocal media project?

Davy $(57, M)$ : Yes. In the province of Limburg, there are two important websites on chess (...) I often send articles to both of them. And now, Het Belang van Limburg provides me with another platform to post my articles.

In general, the interviews revealed three areas where citizen reporters believed they could make a difference, and this is clearly reflected in the stories they contribute. Firstly, many of the interviewees stated to use the hyperlocal news pages as a platform to promote and advertise local community activities organized by the social clubs and organizations for which they work or volunteer. Their hope is that such promotional articles provide useful, practical information to local residents visiting the website. Such practical information can go from notifications of changing opening hours to announcements of upcoming social or cultural events. Eric (32, M), for instance, explained: "The platform helps to reach a lot of people in the community. Many of them have probably heard of the sailing and windsurfing club in our town, but most of them don't know about the upcoming events or planned activities of the club."

A second, and related, reason to contribute to the hyperlocal media platform is to show gratitude and appreciation to the people who helped organize successful community activities. All too often, it was argued, the efforts of many volunteers and supporters behind events remain unnoticed. Some interviewees explicitly mentioned, for example, charity events, which, as Barry $(54, \mathrm{M})$ argued, "deserve to get more attention just because the organizers work hard for a good cause, often without any kind of recognition". This explains the high 
number of reports on successful events and festivities organized by local community organizations.

Thirdly, the interviewees believed their contributions could also offer some kind of counterbalance to all the bad news out there. Francis $(74, M)$ was very clear on this point: "There's already enough bad news in the newspaper, so I'd rather bring positive stories. (...) Sometimes you just want to show what happens in school, or talk about the positive things that are going on in the neighborhood. Positive things happen too, you know." Another interviewee, $\operatorname{Carl}(62, \mathrm{M})$, gave the example of a story he wrote about a local child day care center taking the children for a walk in the park: "That was a great story, I think. I mean, with those pictures of the kids' happy smiling faces, and then the care takers making sure the children got to the location safely. That's what people want to read, no?" As said, most interviewees shared this belief that Het Belang van mijn gemeente should primarily offer positive news about what is going on in the local community. This also explains why they refrained from getting involved in political debates or hard news reporting. According to Eric $(32, \mathrm{M})$, the hyperlocal news platform was not the right place to report on "small conflicts or disagreements in the neighborhood", adding that he also was not "such a citizen reporter who takes pictures of roadworks in his street and then complains about the noise it makes or the dirt on his shoes". The way in which political news is associated here with useless complaints and fruitless negativity recurred in other interviews too.

\subsection{Sources of hyperlocal news}

In this section, we take a closer look into the authorship and sources of the news stories of the citizen and professional journalists. Remarkably, almost all user-generated news items (99\%) mention the full name of the contributor, whereas merely one out of five stories produced by professional journalists $(21 \%)$ mentions the names or initials of the author. Moreover, citizen content is distinguished from professional content by a small symbol of a megaphone before the contributor's name.

Compared to the citizen stories, professional news stories on the platform are more likely to mention the sources of news and information. In total, only 188 of the 474 items analyzed (40\%) contain at least one direct or indirect reference to a source. In other words, six out of ten articles are not transparent about the sources used by the 
author. Professional journalists are more transparent about the sources used than citizen reporters, although for still 33\% of all professional news items it remained unclear which sources had been used by the author. For citizen reports, this percentage is much higher. Over three quarters of all citizen contributions (78\%) do not contain any reference to a source, which is partly due to the fact that citizen reporters primarily draw on personal experience and firsthand witnessing - a finding in line with the study by Reich (2008).

The interviews offer additional support for the idea that due to a lack of access to information sources, citizen journalists tend to rely on their own eyes. Asked to describe the information sources he had used for his story about a cultural event, Barry $(54, \mathrm{M})$, for instance, reacted as follows:

Barry (54, M): "My sources of information? Well, I mean, I was there, so I saw and I listened to what happened. And then I also had a flyer about the event, that provided me with some extra information. And I took pictures myself as well. Well, that's about the information I used for my story."

Interviewer: "Did you also probe for reactions from other participants to the event?

Barry (54, M): "Well... No, actually, I didn't. I never do this."

In line with the literature review and the findings discussed above, professional local journalists refer most often to official sources; especially the police and courts are dominant sources of information to them. Only five professional news items explicitly mentioned a press agency as source of information; yet one must bear in mind that on most occasions when journalists use copy from press agencies, the source is not explicitly mentioned.

The findings of our content analysis confirm that citizen reporters are often relying on personal, firsthand experiences because of a lack of access to official, institutional sources. The citizen stories containing quotes from or references to the mayor, town councilors and politicians were mostly generated by the registered town councils on the platform of Het Belang van mijn gemeente. Similarly, the spokespersons cited or otherwise mentioned as sources in citizen reports are mostly affiliated with the organization for which the citizen reporter works or volunteers. Other citizen stories are completely self-referential, by which we mean that the author is the only source. 


\section{Conclusion}

The online news project Het Belang van mijn gemeente gives a good example of how regional and local newspapers can make use of citizen journalism for community news coverage at a hyperlocal level. The study shows that the community news available on the hyperlocal pages consists of a mix of hard and soft news that is quite similar to what (free) print local newspapers have been offering for years (see Lauterer, 2006; Franklin, 2006). Remarkable, however, is that the 'hard' and factual news about crimes, fires and accidents is still almost exclusively being produced by professional journalists, whereas the 'soft' and 'small' news coverage about daily community life has become the domain of the citizen reporters.

This suggests that community newspapers have come to understand that citizen journalism should not be considered as a cheap surrogate for professional journalism, but as something complementary. These complementarities can be observed at different levels, as we have tried to show in this article. First of all, the differences are apparent in the selection of topics for news coverage. Citizen journalists prefer to create news stories based on their personal interests and experiences, or on information from the local organizations to which they are affiliated. Related to this, a second finding of our study is that, compared to professional journalists, citizens are more likely to use themselves as the primary and often only source for their news stories. Professional local journalists, for their part, tend to rely mainly on official institutional sources like the police and courts.

\section{Acknowledgements}

This study is a part of the SMIF project (Smarter Media in Flanders), a collective research project co-funded by IWT, the Flemish government agency for Innovation by Science and Technology. The authors would like to thank Concentra media group for providing background information about and access to the content management system of Het Belang van mijn gemeente. The authors are also grateful to Evelien Heeren, who collected the interview data for her master's thesis in Journalism at the Erasmus University College Brussels under the supervision of the second author. The analysis presented in this paper has been done by the authors on the original full interview transcripts. 


\section{References}

Bew, R. (2006). The Role of the Freelancer in Local Journalism. In: B. Franklin (Ed.). Local Journalism and Local Media (pp. 200-209). London: Routledge.

Bruns, A. (2011). Citizen Journalism and Everyday Life: A Case Study of Germany's myHeimat.de. In: B. Franklin, \& M. Carlson (Eds.). Journalists, Sources and Credibility: New Perspectives (pp. 182-194). London: Routledge.

Domingo, D., Quandt, T., Heinonen, A., Paulussen, S., Singer, J. B., \& Vujnovic, M. (2008). Participatory Journalism Practices in the Media and Beyond: An International Comparative Study of Initiatives in Online Newspapers. Journalism Practice, 2(3), 326-342.

Franklin, B. (1998). No News Isn't Good News: The Development of Local Free Newspapers. In: B. Franklin, \& D. Murphy (Eds.). Making the Local News (pp. 125139). London: Routledge.

Franklin, B. (Ed.) (2006). Local Journalism and Local Media. London: Routledge.

Flew, T. (2009). Democracy, Participation and Convergent Media: Case Studies in Contemporary Online News Journalism in Australia. Communication, Politics \& Culture, 42(2), 87-109.

Garner, B. (2006). Hungry Media Need Fast Food: The Role of the Central Office of Information. In: B. Franklin (Ed.). Local Journalism and Local Media (pp. 189199). London: Routledge.

Gillmor, D. (2004) We the Media: Grassroots Journalism by the People, for the People. Sebastopol: O'Reilly.

Hamer, M. (2006). Trading on Trust: News Agencies, Local Journalism and Local Media. In: B. Franklin (Ed.). Local Journalism and Local Media (pp. 210-231). London: Routledge.

Hermida, A., \& Thurman, N. (2008). A Clash of Cultures. The Integration of UserGenerated Content Within Professional Journalistic Frameworks at British Newspaper Websites. Journalism Practice, 2(3), 343-356.

Jarvis, J. (2004). Hyperlocal. BuzzMachine, http://buzzmachine.com/2004/02/page/6 (accessed on 10 August 2012).

Jönsson, A. M., \& Örnebring, H. (2011). User Generated Content and the News: Empowerment of Citizens or Interactive Illusion? Journalism Practice, 5(2), 127144.

Lauterer, J. (2006). Community Journalism. Chapel Hill, NC: The University of North Carolina Press.

Metzgar, E. T., Kurpius, D. D., \& ROWLEY, K. M. (2011). Defining Hyperlocal Media: Proposing a Framework for Discussion. New Media \& Society, 13(5), 772-787.

O'Neill, D., \& O'Connor, C. (2008). The Passive Journalist: How Sources Dominate Local News. Journalism Practice, 2(3), 487-500.

Paulussen, S., \& Ugille, P. (2008). User Generated Content in the Newsroom: Professional and Organisational Constraints on Participatory Journalism. Westminster Papers in Communication and Culture (WPCC), 5(2), 24-41.

Paulussen, S., \& D'heer, E. (forthcoming). Using Citizens for Community Journalism. Findings from a Hyperlocal Media Project, Journalism Practice, doi: 10.1080/17512786.2012.756667.

Reich, Z. (2008). How Citizens Create News Stories: The 'News Access' Problem Reversed. Journalism Studies, 9(5), 739-58. 
Reich, Z. (2009). Sourcing the News. New York: Hampton Press.

Ross, K. (2006). Open Source? Hearing Voices in the Local Press. In: B. Franklin (Ed.). Local Journalism and Local Media (pp. 232-244). London: Routledge.

Singer, J. B., Hermida, A., Domingo, D., Heinonen, A., Paulussen, S., Quandt, T., Reich, Z., \& Vujnovic, M. (2011). Participatory Journalism: Guarding Open Gates at Online Newspapers. Malden, MA: Wiley-Blackwell.

Vujnovic, M., Singer, J. B., Paulussen, S., Heinonen, A., Reich, Z., Quandt, T., Hermida, A., \& Domingo, D. (2011). Exploring the Political-Economic Factors of Participatory Journalism. In: B. Franklin (Ed.). The Future of Journalism (pp. 201212). London: Routledge. 